\title{
A reassessment of the genetic determinants, the effect of growth conditions and the availability of an electron donor on the nitrosating activity of Escherichia coli K-12
}

\author{
Rachael Metheringham and Jeff A. Cole
}

Author for correspondence: Jeff A. Cole. Tel: +44 121414 5440. Fax : +44 1214143982.

e-mail : j.a.cole@bham.ac.uk

School of Biochemistry, University of Birmingham, Birmingham B15 2TT, UK

\begin{abstract}
Anaerobic, but not aerobic, cultures of Escherichia coli K-12 catalysed the rapid nitrosation of the model substrate 2,3-diaminonaphthalene when incubated with nitrite. Formate and lactate were effective electron donors for the nitrosation reaction, which was inhibited by nitrate. Optimal growth conditions for the expression of nitrosation activity by various strains and mutants were determined. Highest activities were found with bacteria that had been grown anaerobically in a minimal medium rather than in Lennox broth, with glycerol and fumarate rather than glucose as the main carbon and energy source, and in the presence of a low concentration of nitrate. Bacteria harvested in the early exponential phase were more active than those harvested in later stages of growth. Well-characterized mutants defective in the synthesis of one or more anaerobically induced electron transfer chains were screened for nitrosation activity under these optimal growth conditions: only the respiratory nitrate reductase encoded by the narGHJ operon was implicated as a major contributor to nitrosation activity. Due to the limited sensitivity of the assays currently available, a minor contribution from the two alternative nitrate reductases or even other molybdoproteins could not be excluded. The role of formate in nitrosation was complex and was clearly not limited simply to that of an electron donor in the bacterial reduction of nitrite to nitric oxide: at least two further, chemical roles were inferred. This extensive study of more than 400 independent cultures of $E$. coli K-12 and its derivatives resolved some, but not all, of the apparently conflicting data in the literature concerning nitrosation catalysed by enteric bacteria.
\end{abstract}

Keywords: nitrosation, Escherichia coli, regulation, nitrite reduction, nitrosamine formation

\section{INTRODUCTION}

The formation of $\mathrm{N}$-nitroso compounds by bacteria in the gastro-intestinal tract is widely believed to be a major cause of gastric cancer and the role of nitrite as the precursor of nitrosamines and nitrosamides is well established (Hill et al., 1973; Kunisaki \& Hayashi, 1979; Leach et al., 1979, 1987; Leach, 1995; Reed et al., 1981; Ralt \& Tannenbaum, 1981). Many types of bacteria isolated from humans have been shown to catalyse nitrosation reactions in the laboratory at rates which vary over a very wide range (Calmels et al., 1985, 1987, 1988; De Bernadis et al., 1983). Highest activities were reported for denitrifying bacteria, but these organisms are rarely isolated from the gastro-intestinal tract, even when the $\mathrm{pH}$ of gastric juice is abnormally high due to achlorhydria (Forsythe et al., 1988). Consequently, despite their 10-fold lower catalytic activity, the far larger population of enteric bacteria can be predicted to contribute the majority of nitrosation activity in the human body. This has prompted many studies of the factors which determine the rates of bacterial nitrosation, as assayed with different model substrates (Calmels et al., 1988; Ji \& Hollocher, 1988; Kunisaki \& Hayashi, 1979; O'Donnell \& Edwards, 1992; Ralt et al., 
1988). Most of these reports presented the preliminary results of what was stated to be part of a more comprehensive study, but results from the latter have failed to materialize. Consequently, many contradictory statements can be found in the literature. The closest to a consensus view to emerge is that nitrosation activity involves one or more molybdoproteins that are induced during anaerobic growth under the control of the transcription activator, FNR. The most active and hence the most important enzyme involved in nitrosation was shown to be the respiratory nitrate reductase, NarGHI (Calmels et al., 1988; Ji \& Hollocher, 1988; Ralt et al., 1988). However, subsequent studies implicated the $\mathrm{NADH}$-dependent nitrite reductase rather than nitrate reductase (O'Donnell \& Edwards, 1992). The most recent study confirmed that spontaneous mutagenesis due to nitrosamine formation was dependent upon a molybdoprotein, but apparently eliminated a significant role for the respiratory nitrate reductase in this process (Taverna \& Sedgwick, 1996).

Since the preliminary studies were completed, it has been established that Escherichia coli synthesizes not one but three biochemically and genetically distinct nitrate reductases during anaerobic growth: the two more recently discovered enzymes are the alternative, membrane-bound enzyme, NarZ, encoded by the narZYWV operon and periplasmic nitrate reductase, Nap, encoded by the complex nap-ccm operon (Blasco et al., 1992; Grove et al., 1996). Genes for previously uncharacterized molybdoproteins involved in dimethyl sulphoxide, trimethylamine $\mathrm{N}$-oxide and nitrite reduction, as well as three formate dehydrogenase activities have been cloned and sequenced. In contrast to the earlier studies, the availability of a much wider range of well-characterized mutants has provided the opportunity to investigate whether all three nitrate reductases, the alternative, formate-dependent nitrite reductase, other molybdoproteins involved in formate oxidation or in the reduction of trimethylamine $\mathrm{N}$-oxide and dimethyl sulphoxide can also contribute to the overall rate of bacterial nitrosation.

In all of the previous studies, bacteria were grown overnight to stationary phase before nitrosation activities were determined. In most cases, only a single medium composition, often containing an extremely high, non-physiological concentration of nitrate, was used (but see Calmels et al., 1988 for a partial exception). We have therefore determined how nitrosation activity varies during exponential and stationary phases of growth, during aerobic or anaerobic growth, and during anaerobic growth in the presence or absence of different electron acceptors. The results present a much clearer view of some of the many factors which determine the nitrosation activity of enteric bacteria.

\section{METHODS}

E. coli strains and growth conditions. The $E$. coli $\mathrm{K}-12$ strains used in this study are listed in Table 1.

Unless otherwise stated, bacteria were grown anaerobically at $37^{\circ} \mathrm{C}$ by transferring $5 \mathrm{ml}$ of an aerated, overnight culture into $200 \mathrm{ml}$ minimal salts supplemented with $5 \%(\mathrm{v} / \mathrm{v})$ Lennox broth (LB), $0.4 \%(\mathrm{w} / \mathrm{v})$ glycerol and $40 \mathrm{mM}$ fumarate in an unshaken $250 \mathrm{ml}$ conical flask. Sterile sodium nitrate or sodium nitrite was also added to the medium where noted. In some experiments, the minimal salts medium was replaced by full strength LB and $0.4 \%(\mathrm{w} / \mathrm{v})$ glucose replaced the glycerol and fumarate as the main carbon and energy source. For aerobic cultures, bacteria were grown to the early-exponential phase in $200 \mathrm{ml}$ medium in a well-aerated 2 litre conical flask and harvested at an optical density at $650 \mathrm{~nm}\left(\mathrm{OD}_{650}\right.$ measured using a Phillips PU8720 UV-vis recording spectrophotometer and $1 \mathrm{~cm}$ light path cuvettes) of less than 0.4 (corresponding to a biomass of less than $0 \cdot 15 \mathrm{~g}_{\text {dry mass }}{ }^{-1}$ ).

Preparation of washed bacterial suspensions. Bacteria in the exponential phase of growth were harvested by centrifugation at 7000 r.p.m. for $10 \mathrm{~min}$ at $4{ }^{\circ} \mathrm{C}$, washed twice with PBS (50 $\mathrm{mM} \mathrm{Na}_{2} \mathrm{HPO}_{4}, 50 \mathrm{mM} \mathrm{KH_{2 }} \mathrm{PO}_{4}, \mathrm{pH} 7 \cdot 3$ ) and resuspended in PBS to a density of 7-10 $\mathrm{mg}$ bacterial dry mass $\mathrm{ml}^{-1}$ (corresponding to an $\mathrm{OD}_{650}$ of $0 \cdot 6-0.8$ for a 30 -fold diluted sample). Harvested bacteria were stored on ice for a maximum of $3 \mathrm{~h}$ until assayed.

Determination of the nitrosation rate. Nitrosation was measured as described by Ralt et al. (1988). The analysis is based on the formation of a fluorescent triazole, $1 \mathrm{H}$-naphthol $[2,3-d]$ triazole, following nitrosation of the secondary amine 2,3-diaminonaphthalene (DAN).

A series of $1.5 \mathrm{ml}$ closed Eppendorf tubes containing (final concentration) bacterial suspension $(0.753 \mathrm{mg}$ dry bacteria $\mathrm{ml}^{-1}$ ), DAN $(0.46 \mathrm{mM}$ ) and electron donor (usually $20 \mathrm{mM}$ formate) were equilibrated to $37^{\circ} \mathrm{C}$ and the reaction was started by the addition of a solution of sodium nitrite (to $25 \mathrm{mM}$ ). The final volume in each tube was $0.6 \mathrm{ml}$. At $5 \mathrm{~min}$ intervals for $30 \mathrm{~min}$ tubes were plunged into slush ice to stop the reaction and bacteria were sedimented by centrifugation. Part of the supernatant $(0.3 \mathrm{ml})$ was transferred to tubes containing $2.7 \mathrm{ml}$ PBS and the fluorescence was determined using a Perkin Elmer 1000 fluorescence spectrophotometer at an excitation wavelength of $375 \mathrm{~nm}$ and emission wavelength of $450 \mathrm{~nm}$. As $1 H$-naphthol [2,3-d] triazole could not be obtained commercially, a calibration curve for the fluorimeter was constructed using 7-amino-4-methylcoumarin, which emits fluorescence at the same wavelength. To convert fluorescence measurements to quantities of DAN converted, a further calibration curve was established by incubating excess bacteria with a series of limiting quantities of DAN until the reaction had proceeded to completion. This revealed that 10 units of fluorescence correspond to $1 \mathrm{nmol} 1 \mathrm{H}$-naphthol [2,3d] triazole under the stated conditions. In subsequent sections, 1 unit of nitrosation activity corresponds to $1 \mathrm{nmol} 1 \mathrm{H}$ naphthol [2,3-d] triazole formed (mg dry bacteria) ${ }^{-1} \mathrm{~min}^{-1}$.

Nitrate reductase activity. Bacteria which had been grown overnight in $500 \mathrm{ml}$ Lennox broth supplemented with $0.4 \%$ glucose and $20 \mathrm{mM}$ potassium nitrate were harvested by centrifugation $(10000 \mathrm{~g} ; 5 \mathrm{~min})$, resuspended in $5 \mathrm{ml} 50 \mathrm{mM}$ potassium phosphate buffer, sedimented by centrifugation as above and resuspended in $5 \mathrm{ml}$ fresh phosphate buffer. Samples were transferred to a $10 \mathrm{ml}$ water-jacketed reaction vessel and a nitrate electrode coupled to an Ion Meter (Spectronic Analytical Instruments) was used to determine the rate of nitrate reduction at $30^{\circ} \mathrm{C}$ in the presence or absence of $40 \mathrm{mM}$ sodium formate. 
Table 1. Strains of $E$. coli $\mathrm{K}-12$ used and their source

\begin{tabular}{|c|c|c|}
\hline Strain & Genotype or phenotype & Source \\
\hline DSS401 & $d m s$ derivative of $\mathrm{MC} 4100$ & $\begin{array}{l}\text { M. Chippaux \& G. Giordano, } \\
\text { CNRS, Marseilles, France }\end{array}$ \\
\hline JCB387 & $\Delta$ nir derivative of strain $\mathrm{RV}$ & Darwin et al. (1993) \\
\hline JCB322 & $\mathrm{Chl}^{\mathrm{R}}$ derivative of JCB387 & Griffiths \& Cole (1987) \\
\hline JCB323 & $\mathrm{Ch}^{\mathrm{R}}$ derivative of $\mathrm{JCB} 387$ & Griffiths \& Cole (1987) \\
\hline JCB606 & $\operatorname{dip} \mathrm{Z}$ derivative of $\mathrm{JCB} 387$ & Crooke \& Cole (1995) \\
\hline JCB3876 & $f d h F$ derivative of JCB387 & Darwin et al. (1993) \\
\hline JCB3877 & $f d n G$ derivative of $\mathrm{JCB} 387$ & Darwin et al. (1993) \\
\hline JCB3878 & $\Delta(n r f-f d h F)$ derivative of JCB387 & Darwin et al. (1993) \\
\hline JCB3881 & sel::: $\mathrm{Kan}^{\mathrm{R}}$ derivative of $\mathrm{JCB} 387$ & Darwin et al. (1993) \\
\hline JCB3882 & $f d n G f d h F$ fdo derivative of JCB387 & Darwin et al. (1993) \\
\hline JCB38700 & $\Delta$ nir narG derivative of JCB387 & This work \\
\hline JCB38701 & $\Delta$ nir nar $Z$ derivative of JCB387 & This work \\
\hline JCB38702 & $\Delta$ nir napA derivative of JCB387 & This work \\
\hline JM712 & pro his trp $\Delta l a c$ & $\begin{array}{l}\text { M. Jones-Mortimer, Mold, } \\
\text { Clwyd, UK }\end{array}$ \\
\hline LCB628 & tor derivative of MC4100 & $\begin{array}{l}\text { M. Chippaux \& G. Giordano, } \\
\text { CNRS, Marseilles, France }\end{array}$ \\
\hline MC4100 & araD $\Delta(\arg F-l a c)$ ptsF deoC flbB relA rpsL & Casadaban \& Cohen (1979) \\
\hline RV & Prototroph; parent of JCB strains & $\begin{array}{l}\text { T. Young, University of } \\
\text { Birmingham, UK }\end{array}$ \\
\hline RV5265 & nar $G$ derivative of strain $\mathrm{RV}$ & This work \\
\hline
\end{tabular}

\section{RESULTS}

\section{Nitrosation of DAN by $E$. coli and its inhibition by nitrate}

Initial attempts to detect nitrosation of DAN by anaerobically grown cultures of several E. coli strains were unsuccessful. Calmels et al. (1988) reported that nitrate in the reaction mixture strongly inhibits in vitro nitrosation. To test the possibility that inability to detect nitrosation activity was due to the carry-over of nitrate from the growth medium, $E$. coli strain RV was grown anaerobically in LB supplemented with $0.4 \%$ glycerol, $40 \mathrm{mM}$ fumarate and $100 \mathrm{mM}$ nitrate, harvested, washed twice with PBS and resuspended in PBS. Nitrosation activity was readily detected when bacteria had been washed and assayed in the absence of nitrate or growth medium, either in the presence or absence of formate, with rates significantly higher than the chemical rate (Fig. 1). Higher rates were detected when bacteria were assayed with the electron donor formate. Nitrosation activity was strongly inhibited by the growth medium and to a lesser extent in the presence of $10 \mathrm{mM}$ nitrate. It can be concluded that carry-over of nitrate from the growth medium into reaction mixtures to be assayed was responsible for the failure to detect nitrosation activity in previous experiments.

The rate of nitrosation was assayed in the presence or absence of the potential electron donors lactate, ethanol, glucose, succinate, pyruvate and formate. The highest rate, 310 units nitrosation activity [nmol $1 H$-naphthol [2,3-d] triazole formed (mg dry bacteria) $)^{-1} \mathrm{~h}^{-1}$, was observed with formate. Rates in the presence of lactate were $75 \%$ and with glucose around $50 \%$ of the maximum activity ( 210 and 140 units, respectively), but rates in the presence of succinate, ethanol and pyruvate were comparable to the endogenous rate in the absence of an electron donor. In subsequent experiments bacteria were assayed in the presence and absence of $20 \mathrm{mM}$ formate as the electron donor.

\section{Nitrosation rates and formate-dependence of nitrosation activity in bacteria at various stages of growth}

In most of the previous studies of nitrosation catalysed by $E$. coli, bacteria were grown overnight to stationary phase in media containing $100 \mathrm{mM}$ nitrate, a concentration far higher than that encountered in vivo which rarely, if ever, exceeds $1 \mathrm{mM}$ (Forsythe et al., 1988). In initial experiments to determine the effect of growth phase on the nitrosation rates and formatedependence of nitrosation, E. coli strain RV was grown anaerobically in minimal salts supplemented with $0.4 \%$ glycerol, $40 \mathrm{mM}$ fumarate and, in parallel experiments, with either $5 \mathrm{mM}$ or $100 \mathrm{mM}$ nitrate. Bacteria in the middle- and late-exponential and stationary phases of growth were collected by centrifugation, washed twice, resuspended in PBS and then assayed with or without formate. The highest formate-dependent rate of nitrosation was catalysed by bacteria which had been 


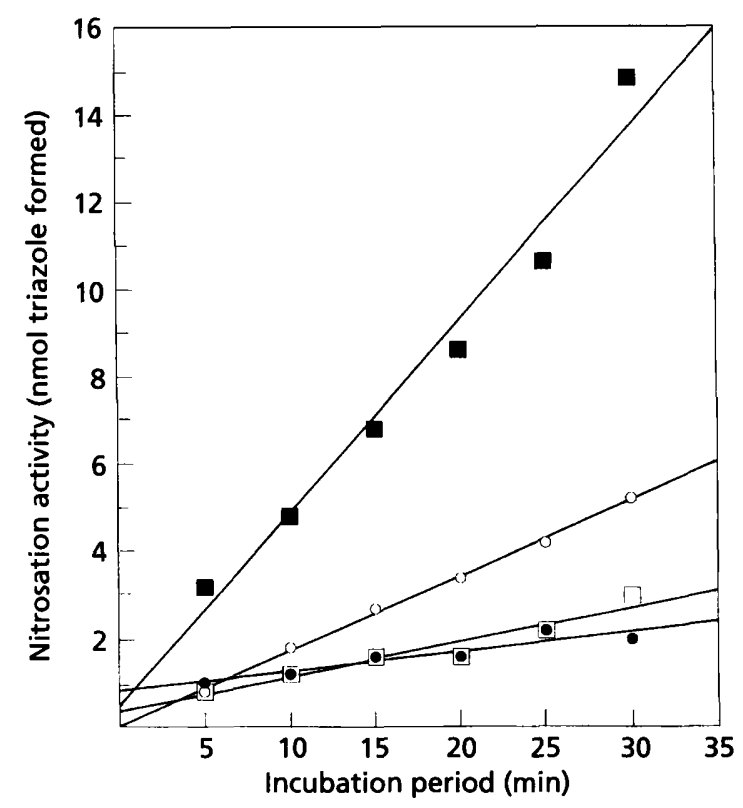

Fig. 1. Nitrosation of DAN by $E$. coli and its inhibition by nitrate. E. coli strain RV was grown anaerobically in $250 \mathrm{ml}$ flasks filled with Lennox broth supplemented with $0.4 \%$ glycerol, $40 \mathrm{mM}$ fumarate and $100 \mathrm{mM}$ nitrate. Bacteria in the stationary phase were harvested, washed and assayed for nitrosation activity in the presence or absence of formate and nitrate. $\square$, Formate, no nitrate; $\bigcirc$, no formate, no nitrate; $\square$, formate plus nitrate; $\mathbf{0}$, formate plus growth medium.

harvested in the middle of the exponential phase of growth. The formate-dependent activity of bacteria harvested in the late exponential phase was around $70 \%$ of the maximum $450 \pm 37$ units of activity observed during the middle of the exponential phase of growth. The nitrosation rates of bacteria harvested in the stationary phase of growth were more variable, typically in the range $50-70 \%$ of the fully induced rate during exponential growth. Endogenous rates of bacteria harvested in all three stages of growth were consistently far lower than rates in the presence of formate $(47 \pm 1$ units for exponential-phase cultures; $16 \pm 3$ units for lateexponential-phase cultures and $18 \pm 1$ units for stationary-phase cultures).
In a further series of experiments, nitrosation activities of independent cultures of bacteria which had been grown in different batches of culture medium and harvested either in the middle of the exponential phase or in the stationary phase of growth were compared (Table 2). Not only were stationary-phase bacteria less active, but both the rates detected and the effect of formate on nitrosation activity were more variable than those of exponential-phase bacteria. In all subsequent experiments bacteria were harvested in the middle of the exponential phase of growth to achieve optimal nitrosation activity.

\section{The effect of culture conditions on the induction of nitrosation activity in E. coli strain RV}

To determine the optimal growth conditions for the development of nitrosation activity, E. coli strain RV was grown anaerobically in either Lennox broth or minimal medium in the presence of either $0.4 \%$ glycerol and $40 \mathrm{mM}$ fumarate or $0.4 \%$ glucose as the main sources of carbon and energy. Some cultures were supplemented with sodium nitrate or nitrite. Bacteria were harvested in the exponential phase of growth, washed and assayed for nitrosation activity in the presence or absence of formate.

Rates of nitrosation by bacteria which had been grown in rich media were consistently lower than those grown in minimal media, irrespective of whether the carbon and energy source was glucose or glycerol and fumarate (Table 3). Furthermore, the rate of nitrosation in the presence of formate was significantly or far higher than the chemical rate. With one exception, nitrosation rates were also far higher in the presence of formate than in its absence. However, the endogenous rate of nitrosation was consistently higher than the rate in the presence of formate when bacteria had been grown in minimal medium with glycerol and fumarate but in the absence of nitrate or nitrite. Highest formate-dependent rates of nitrosation were found with bacteria that had been grown in minimal medium supplemented with glycerol, fumarate and a low concentration of nitrate. Nitrosation activity was not induced during growth in the presence of nitrite. No nitrosation activity could be detected in bacteria which had been grown aerobically.

Table 2. Nitrosation activities of independent cultures of bacteria harvested either in the middle of the exponential phase or in the stationary phase of growth

Nitrosation activity is expressed as nmol $1 \mathrm{H}$-naphthol $[2,3-d]$ triazole formed (mg dry bacteria) $)^{-1} h^{-1}$.

\begin{tabular}{|lccccc|}
\hline $\begin{array}{l}\text { Growth } \\
\text { phase }\end{array}$ & $\begin{array}{c}\text { Formate in } \\
\text { assay }\end{array}$ & $\begin{array}{c}\text { No. of } \\
\text { cultures }\end{array}$ & Mean & Range & $\begin{array}{c}\text { Standard } \\
\text { deviation }\end{array}$ \\
\hline Exponential & - & 7 & 6 & $4-12$ & $4 \cdot 2$ \\
Stationary & + & 7 & 329 & $242-402$ & 70 \\
& - & 4 & 21 & $<1-50$ & 21 \\
& + & 5 & 212 & $107-373$ & 102 \\
\hline
\end{tabular}


Table 3. Effect of composition of the growth medium on nitrosation activity by the wild-type $E$. coli strain RV

\begin{tabular}{|c|c|c|c|c|}
\hline \multicolumn{3}{|c|}{ Culture conditions ${ }^{*}$} & \multicolumn{2}{|c|}{ Nitrosation activity $\dagger$} \\
\hline Medium & Carbon source & Supplements & Endogenous & $\begin{array}{l}\text { Formate- } \\
\text { dependent }\end{array}$ \\
\hline LB & Glucose $(0.4 \%)$ & $\mathrm{NaNO}_{3}(100 \mathrm{mM})$ & $<10$ & $350 \pm 3 \cdot 5$ \\
\hline LB & Glycerol $(0 \cdot 4 \%)+$ fumarate $(40 \mathrm{mM})$ & $\mathrm{NaNO}_{3}(100 \mathrm{mM})$ & $<10$ & $350 \pm 13$ \\
\hline MM & Glucose $(0.4 \%)$ & $\mathrm{NaNO}_{3}(100 \mathrm{mM})$ & $22 \pm 2$ & $86 \pm 9$ \\
\hline MM & Glycerol $(0.4 \%)+$ fumarate $(40 \mathrm{mM})$ & No supplement & $434 \pm 31$ & $232 \pm 26$ \\
\hline MM & Glycerol $(0.4 \%)+$ fumarate $(40 \mathrm{mM})$ & $\mathrm{NaNO}_{3}(5 \mathrm{mM})$ & $11 \pm 9 \cdot 5$ & $399 \pm 11 \cdot 4$ \\
\hline MM & Glycerol $(0 \cdot 4 \%)+$ fumarate $(40 \mathrm{mM})$ & $\mathrm{NaNO}_{3}(100 \mathrm{mM})$ & $20 \pm 2 \cdot 9$ & $253 \pm 6$ \\
\hline MM & Glycerol $(0 \cdot 4 \%)+$ fumarate $(40 \mathrm{mM})$ & $\mathrm{NaNO}_{2}(2.5 \mathrm{mM})$ & $<10$ & $199 \pm 2 \cdot 5$ \\
\hline
\end{tabular}

"Bacteria were grown anaerobically in either minimal salts medium (MM) or Lennox broth (LB) supplemented as shown, washed and assayed anaerobically in the presence of $20 \mathrm{mM}$ sodium nitrite with or without $20 \mathrm{mM}$ formate as the electron donor.

$\dagger$ Nitrosation activity is expressed as nmol $1 H$-naphthol $[2,3-d]$ triazole formed $\left(\right.$ mg dry bacteria) ${ }^{-1} \mathrm{~h}^{-1}$. The chemical rate, $8 \cdot 5 \pm 1$, was deducted from all values. Values are means \pm SD of two to four assays.

\section{Nitrosation activity in $E$. coli mutants deficient for a combination of nitrate and nitrite reductases}

Although the respiratory nitrate reductase encoded by the narGHJI operon was implicated as the major source of nitrosating activity (Ralt et al., 1988; Ji \& Hollocher, 1988; Calmels et al., 1988), two subsequent studies have led to opposite conclusions. O'Donnell \& Edwards (1992) concluded from studies of a nir mutant, strain LCB82, that the NADH-dependent nitrite reductase was a major contributor. In contrast, on the basis of comparisons of mutagenesis caused by nitrosamine formation by a nar $G$ mutant and a moa mutant which is unable to synthesize the molybdenum cofactor essential for all nitrate reductase activity, Taverna \& Sedgwick (1996) concluded that a molybdoprotein was involved, but the respiratory nitrate reductase was not essential. A possible explanation for the conflict between these studies is that since 1988 it has been recognized that $E$. coli synthesizes multiple nitrate and nitrite reductases encoded by operons that have only recently been cloned and sequenced (Blasco et al., 1992; Darwin et al., 1993; Grove et al., 1996; Hussain et al., 1994). The growth conditions used previously were not optimal either for the induction of nitrosation activity or for the expression of the operons for these alternative reductases, so the possibility that nitrosation activity is catalysed by these alternative enzymes, either as well as or instead of Nir and NarG, has not been assessed. As Nap and Nrf activities are both expressed optimally during anaerobic growth with a limiting concentration of nitrate or nitrite, conditions under which $\mathrm{Nar} Z$ and $\mathrm{Nir}$ are also expressed (Darwin et al., 1993; Grove et al., 1996), a series of wellcharacterized mutants defective in genes known to be essential for the synthesis of all known anaerobically induced electron transfer pathways in E. coli were grown anaerobically in the presence of $5 \mathrm{mM}$ nitrate and assayed under optimal conditions to identify which enzymes are directly implicated in the nitrosation reaction.
The rate of nitrosation by strain JCB387, which lacks only the major, NADH-dependent nitrite reductase, was similar to that of the parental strain, RV (Table 4). As this is a deletion mutant, the possibility that the sirohaem-dependent but molybdopterin-independent nitrite reductase is a major contributor to nitrosation activity can be excluded (O'Donnell \& Edwards, 1992). Strain JCB387 was the parent of many of the strains used in this study. Genes for the alternative, formatedependent nitrite reductase have been deleted from strain JCB3878; this strain was also as active as the parental strain in the nitrosation assay. In contrast, no nitrosation activity was detected in two chlorateresistant mutants, strains JCB322 and JCB323, which lack all molybdoproteins due to their inability to synthesize the molybdopterin cofactor. This agrees with previous reports that nitrosation activity requires the activity of one or more molybdoproteins (Calmels et al., 1987; Ralt et al., 1988; Ji \& Hollocher, 1988). Note that fumarate reductase activity and the presence of fumarate in the medium were essential for the growth of these moa strains; this excludes the formal but unlikely possibility that fumarate reductase contributes significantly to nitrosation activity.

Three anaerobically expressed electron transfer chains are known to require $c$-type cytochromes to transfer electrons from the quinone pool to the terminal reductase. Two of these reductases, $\mathrm{Nap}$ and the trimethylamine- $N$-oxide reductase, Tor, are molybdoproteins. Strain JCB606 is unable to synthesize any of the five known $c$-type cytochromes in $E$. coli and is therefore $\mathrm{Nrf}^{-}, \mathrm{Nap}^{-}$and $\mathrm{Tor}^{-}$. The nitrosation activity of strain JCB606 was the same (or possibly slightly higher) than that of the parental strain.

Finally, mutants defective in each of the three known nitrate reductases were constructed. Only the mutant lacking the major, respiratory nitrate reductase encoded by the narGHJI operon was severely defective in nitrosation activity (Table 4). Furthermore, no nitro- 
Table 4. Genetic determinants of nitrosation activity by $E$. coli

\begin{tabular}{|c|c|c|c|}
\hline \multirow[t]{2}{*}{ Strain } & \multirow[t]{2}{*}{ Relevant genotype } & \multicolumn{2}{|c|}{ Nitrosation activity ${ }^{*}$} \\
\hline & & Endogenous & $\begin{array}{l}\text { Formate- } \\
\text { dependent }\end{array}$ \\
\hline RV & Parental strain & $11 \pm 9 \cdot 5$ & $399 \pm 11 \cdot 4$ \\
\hline JCB387 & $\Delta n i r$ & $<10$ & $304 \pm 10 \cdot 5$ \\
\hline JCB322 & $\Delta$ nir moat & $<10$ & $<10$ \\
\hline JCB323 & $\Delta$ nir moa $\dagger$ & $<10$ & $<10$ \\
\hline JCB606 & $\Delta n i r \operatorname{dip} Z$ & $<10$ & $433 \pm 23$ \\
\hline JCB3878 & $\Delta n i r n r f$ & $<10$ & $333 \pm 20$ \\
\hline JCB38700 & $\Delta$ nir narG & $<10$ & $<10$ \\
\hline RV5265 & $n a r G$ in $\mathrm{RV}$ & $<10$ & $<10$ \\
\hline JCB38701 & $\Delta$ nir narZ & $<10$ & 450 \\
\hline JCB38702 & $\Delta$ nir nap $A:: \Omega$ & $<10$ & 539 \\
\hline \multicolumn{4}{|c|}{$\begin{array}{l}\text { Isogenic strains in the } \\
\text { MC } 4100 \text { background }\end{array}$} \\
\hline MC4100 & Wild-type & $<10$ & 205 \\
\hline LCB628 & tor & $<10$ & 125 \\
\hline DSS401 & $d m s$ & $<10$ & 165 \\
\hline
\end{tabular}

" Nitrosation activity is expressed as nmol $1 H$-naphthol $[2,3-d]$ triazole formed $(\text { mg dry bacteria })^{-1} \mathrm{~h}^{-1}$. Values are means \pm SD of two to four assays; where no SD is given, values are means of two independent assays.

† moa, chlorate-resistant strain due to a mutation in genes essential for the synthesis of the prosthetic group of nitrate reductase and other molybdoproteins, molybdopterin guanine dinucleotide.

sation activity was detected when the nar $G$ mutant was grown in the absence of nitrate, or with excess nitrate (data not shown). We conclude that the requirement for anaerobic growth and the stimulatory effect of nitrate during growth on the development of nitrosation activity was due to the induction of the NarGHI complex. Consistent with this conclusion and in agreement with an earlier report by Ralt et al. (1988), nitrosation activity increased in parallel with the induction of nitrate reductase activity when strain JCB387 was grown anaerobically in the presence or absence of $2.5 \mathrm{mM}$ nitrite or $100 \mathrm{mM}$ nitrate (data not shown). These combined results establish that neither Nap nor NarZ contribute significantly to the overall rate of nitrosation by E. coli, which is directly dependent on the presence of the membrane-bound nitrate reductase encoded by the narGHJI operon in E. coli.

\section{Nitrosation activity of strains defective in formate dehydrogenase activity}

The electron donor in this and other studies was formate, which is oxidized by three biochemically and genetically distinct formate dehydrogenases, all of which are molybdoproteins. The effects of mutations resulting in the loss of one or all of these activities was therefore investigated. The major formate dehydrogenase induced during anaerobic respiratory growth in the presence of nitrate is Fdn (Berg \& Stewart, 1990; Berg et al., 1991). During anaerobic growth, transcription of the $f d n G H I$ operon is activated coordinately with the respiratory nitrate reductase operon, narGHJI, by two transcription factors, FNR and NarL (Rabin \& Stewart, 1993; Stewart, 1993); however, the rate of formate-dependent nitrosation by the Fdn mutant, JCB3877, was similar to that of the parental strain, JCB387 (Table 5). The same was true for strain JCB3876 which lacks the formate dehydrogenase formed during fermentative growth, $\mathrm{FDH}_{\mathrm{H}}$; this enzyme couples formate oxidation to $\mathrm{H}^{+}$ reduction by the formate hydrogenlyase complex (Peck \& Gest, 1957; Gest \& Peck, 1955; Gray \& Gest, 1965; Böhm et al., 1990; Sauter et al., 1992). Particularly surprising was the observation that formate still stimulated nitrosation by two mutants which lack all three known formate dehydrogenases (Table 5). One of these strains, JCB3882, carries three separate mutations in each of the three operons encoding the formate dehydrogenases; the other strain, JCB3881, is pleiotropically negative due to the deletion of a gene required for the insertion of an essential selenocysteine residue in all three formate dehydrogenase molybdoproteins (Pinsent, 1954 ; Lester \& DeMoss, 1971; Sawers et al., 1991). Two further tests were used to confirm that these mutants had been constructed correctly and had not reverted. First, they were both shown to be defective for formate hydrogenlyase activity, a reaction that requires a functional $f d h F$ gene encoding $\mathrm{FdhH}$. Secondly, their rates of nitrate reduction in the presence and absence of formate were compared with those of the parental strain, JCB387. The slow endogenous rate of nitrate reduction by washed suspensions of the parental strain increased more than 10-fold upon additon of formate [from 30 to 
Table 5. Nitrosation activities of formate dehydrogenase mutants after growth in the presence or absence of nitrate

\begin{tabular}{|c|c|c|c|c|}
\hline \multirow[t]{2}{*}{ Strain } & \multirow{2}{*}{$\begin{array}{l}\text { Culture } \\
\text { conditions" }\end{array}$} & \multirow{2}{*}{$\begin{array}{l}\text { Relevant } \\
\text { genotype }\end{array}$} & \multicolumn{2}{|c|}{ Nitrosation activity $\nmid$} \\
\hline & & & Endogenous & $\begin{array}{l}\text { Formate- } \\
\text { dependent }\end{array}$ \\
\hline JCB387 & $\begin{array}{l}\text { - Nitrate } \\
+ \text { Nitrate }\end{array}$ & E. coli $\mathrm{RV} \Delta$ nir $B$ & $\begin{array}{l}434 \\
220\end{array}$ & $\begin{array}{l}266 \\
506\end{array}$ \\
\hline JCB3876 & $\begin{array}{l}\text { - Nitrate } \\
+ \text { Nitrate }\end{array}$ & JCB387 $f d b F$ & $\begin{array}{r}422 \\
79\end{array}$ & $\begin{array}{l}306 \\
413\end{array}$ \\
\hline JCB3877 & $\begin{array}{l}\text { - Nitrate } \\
\text { + Nitrate }\end{array}$ & $\mathrm{JCB} 387 f d n G$ & $\begin{array}{l}453 \\
224\end{array}$ & $\begin{array}{l}288 \\
454\end{array}$ \\
\hline JCB3881 & $\begin{array}{l}\text { - Nitrate } \\
+ \text { Nitrate }\end{array}$ & JCB387 $\Delta s e l:: k a n$ & $\begin{array}{l}437 \\
244\end{array}$ & $\begin{array}{l}320 \\
472\end{array}$ \\
\hline JCB3882 & $\begin{array}{l}\text { - Nitrate } \\
+ \text { Nitrate } \\
\end{array}$ & $\mathrm{JCB} 387 f d n G f d h F f d o$ & $\begin{array}{l}270 \\
146\end{array}$ & $\begin{array}{l}251 \\
356\end{array}$ \\
\hline
\end{tabular}

* Bacteria were grown in minimal salts supplemented with $0.4 \%$ glycerol, $40 \mathrm{mM}$ fumarate, $5 \%$ LB with or without $5 \mathrm{mM}$ nitrate.

†Nitrosation activity is expressed as nmol $1 \mathrm{H}$-naphthol $[2,3-d]$ triazole formed (mg dry bacteria) $)^{-1} \mathrm{~h}^{-1}$. Values are means of two independent assays.

$310 \mathrm{nmol}$ of nitrate reduced (mg dry bacteria) ${ }^{-1} \mathrm{~min}^{-1}$ ]. In contrast, no formate-dependent increase in rate was detected with either of the mutants. These observations suggest that the primary role of formate in nitrosation is to supply reductant for a chemical rather than an enzymic reaction. An alternative, but unlikely possibility is that there is a fourth, currently uncharacterized formate dehydrogenase in $E$. coli. If so, this fourth enzyme must be sufficient to sustain full nitrosation activity; furthermore, it cannot be a selenoprotein.

\section{Effect of aeration during the assay on the rate of nitrosation}

Previous data indicated that bacteria grown in the absence of nitrate or nitrite catalyse a higher rate of nitrosation in the absence of formate than in its presence (Table 3). Furthermore, the endogenous rate of nitrosation by these bacteria is similar to that of bacteria grown anaerobically with nitrate and assayed in the presence of formate. Several possible explanations for this inhibition of nitrosation by formate were considered. Two of the initial stages in the nitrosation reaction are the enzyme-catalysed formation of nitric oxide followed by the spontaneous, but oxygen-dependent, chemical oxidation of the complex formed between $\mathrm{NO}$ and the nitrosated substrate ( $\mathrm{Ji} \&$ Hollocher, 1988). It is conceivable that formate inhibits one or other of these two stages, or at some stage competes for a key substrate such as the nitrosated intermediate or oxygen. Any explanation must also account for the differences between bacteria that are only partially induced for nitrosation and those that are more fully induced.
To test whether oxygen was limiting in the second stage of the nitrosation reaction, strain $\mathrm{RV}$ was grown anaerobically in minimal medium supplemented with $0.4 \%$ glycerol and $40 \mathrm{mM}$ fumarate in the presence or absence of $5 \mathrm{mM}$ nitrate. Bacteria were harvested in the exponential phase of growth, washed and assayed in the presence or absence of formate in $25 \mathrm{ml}$ flasks which were either vigorously aerated during the assay, or left unshaken. The rates of nitrosation catalysed by bacteria that were aerated during the assay were approximately $50 \%$ of those that were not aerated. Furthermore, bacteria which had been grown in the absence of nitrate attained higher rates of nitrosation in the absence of formate than in its presence ( 120 units for the aerated sample in the absence of formate and 90 units in the presence of formate, compared with 230 and 200 units, respectively, for the samples that were not aerated during the nitrosation assay). In contrast, endogenous rates were suppressed and formate-dependent rates were higher when bacteria were grown in media supplemented with nitrate (120 and 67 units for the aerated samples assayed in the presence or absence of formate compared with 350 and 120 units for the unaerated assay samples, respectively). In conclusion, the consistently higher endogenous rate than the rate in the presence of formate by bacteria that had been grown in the absence of nitrate or nitrite cannot be explained simply by a formate-enhanced oxygen deficiency during the nitrosation reaction.

\section{DISCUSSION}

Although the ability of enteric bacteria to catalyse nitrosation is well-established, preliminary attempts to identify the enzymes involved have led to conflicting 
conclusions. More than 400 independent cultures of well-characterized $E$. coli strains grown under a variety of conditions have enabled us to resolve some, but not all, of the apparent discrepancies in the literature. These experiments have provided the first systematic analysis of the relative roles of all known anaerobically induced electron transfer pathways in E. coli in nitrosation, how nitrosation activity varies with growth conditions, and the role of formate as an electron donor for the nitrosation reaction. Preliminary experiments (data not shown) established that E. coli strain RV, which was used for most of these experiments, expressed slightly higher nitrosation activity than E. coli strain M182 and threefold higher activity than strain JM712; all three of these strains have been used previously in this laboratory to study the regulation of anaerobically expressed electron transfer chains (Hussain et al., 1994; Grove et al., 1996).

\section{Genetic determinants of nitrosation activity}

The availability of a comprehensive range of mutants defective in each of the known anaerobic respiratory pathways of $E$. coli has enabled us to confirm previous reports that the major, respiratory nitrate reductase is essential for virtually all of the nitrosation activity (Calmels et al., 1988; Ralt et al., 1988; Ji \& Hollocher, 1988). Although the assay used to measure nitrosation rates is the most sensitive currently available (Ralt $e t$ al., 1988), the lower limit of detection is still rather high, about $1 \%$ of the optimal rate detected in fully induced bacteria. The strains used in this study were grown under conditions optimal for Nap and NarZ expression; nevertheless, we estimate that these alternative enzymes contribute less than $5 \%$ to the total rate of nitrate reduction (G. Thomas, L. Potter \& J. A. Cole, unpublished results). Any gratuitous conversion of nitrite to nitric oxide by NarZ or Nap at a specific activity similar to that of the major, respiratory nitrate reductase would be too slow to be detected reliably by this assay. Consequently, although a major contribution by other enzymes can be excluded, it is not possible to state that they do not contribute at all to the overall rate of nitrosation.

\section{Dependence of nitrosation activity on the growth conditions}

Factors which influence the nitrosation activity of E. coli include the phase at which bacteria are harvested, whether bacteria are grown aerobically or anaerobically, the carbon source and the richness of the medium, and the electron acceptor available during anaerobic growth.

In none of the previous studies was the effect of growth phase on nitrosation activity reported, but Ralt et al. (1988) commented that similar activities were found with exponential-phase and overnight cultures. However, no additional carbon source was added by these authors to support growth, so it is not clear whether the cultures used had entered the stationary phase when the bacteria were harvested after overnight growth. The nitrosating activity of several strains used in this study was twice as high in exponentially growing bacteria as in those harvested after overnight growth (typically about $16 \mathrm{~h}$ ). Furthermore, the endogenous rate of nitrosation in the absence of an added electron donor was often much greater than that of exponential-phase cultures. We were unable to establish a correlation between this increase and either the disappearance of nitrate from the culture or with the accumulation of nitrite during growth.

A critical factor in determining the nitrosation activity of cultures was the degree of aeration. Contrary to the results of O'Donnell \& Edwards (1992), virtually no activity was detected in bacteria grown in well-aerated cultures. Control experiments in this laboratory in which an oxygen electrode was suspended in $400 \mathrm{ml}$ of medium in a 'well-aerated' 2 litre conical flask revealed that the culture effectively became oxygen-limited when the density approached $0.15 \mathrm{mg}$ dry bacteria $\mathrm{ml}^{-1}$ (corresponding to an $\mathrm{OD}_{650}$ of only $0 \cdot 4$ ). At this density of bacteria, most anaerobically induced electron transfer chains which are activated by the FNR protein are at least partially derepressed (unpublished observations). Consequently, it is essential to harvest bacteria at an early stage in the growth cycle for effects of oxygen on metabolism to be assessed reliably. It is not clear whether this requirement was satisfied in the earlier studies.

In most of the previous studies, bacteria were grown in a rich broth supplemented with very high concentrations of nitrate. It is now clear that such conditions are far from optimal for the development of nitrosation activity, which was far higher after anaerobic growth in a minimal salts medium than in a rich broth. It was also induced strongly by nitrate, but partially repressed by glucose. Higher activities were detected in bacteria that had been grown with a low, limiting concentration of nitrate, $5 \mathrm{mM}$, than with an unphysiologically high concentration, $100 \mathrm{mM}$. Nitrite accumulated in both types of culture and was present when the bacteria were harvested, but nitrate was still present only in the culture grown with the higher nitrate concentration. Measurement of the nitrate reductase activity of some cultures confirmed earlier reports that nitrosation activity increased with increasing nitrate reductase activity, but strict proportionality between the two was not established. This implies that other factors also determine the nitrosation activity of a culture. Note particularly the very high nitrosation activity of bacteria grown in the absence of nitrate and assayed in the absence of an added electron donor (Table 3). Nitrate reductase activity was only weakly induced in these cultures.

\section{A surprising role for formate in bacterial nitrosation}

Nitrosation of model substrates such as DAN proceeds in two distinct stages, the enzymic reduction of nitrite to nitric oxide, followed by a series of chemical reactions in which $\mathrm{O}_{2}$ is thought to form the direct nitrosylating species, $\mathrm{N}_{2} \mathrm{O}_{3}$ and $\mathrm{N}_{2} \mathrm{O}_{4}$ (Ji \& Hollocher, 1988). Electrons are required for the first reaction, and formate 
is recognized as a preferred electron donor for the respiratory nitrate reductase (Ruiz-Herrera \& DeMoss, 1969 ; Enoch \& Lester, 1975). Other E. coli fermentation products as well as NADH generated during catabolism can also donate electrons to nitrate reductase. The role of formate in enhancing the rate of nitrosation, and the ability of lactate, pyruvate or glucose to replace formate, all suggest that the primary role of the electron donor is to provide electrons for nitrite reduction to NO by nitrate reductase. If so, mutants defective in formate dehydrogenase activity should be defective in formatedependent nitrosation. This was not observed (Table 5). This suggests that formate must fulfill a chemical role in nitrosation, possibly acting as a reducing agent. Such a role would be consistent with the observation of Ji \& Hollocher (1988) that formate has little effect on the yield of triazole if bacteria are incubated with nitrite and DAN under strictly anaerobic conditions. Note, however, that the role of formate cannot be to remove oxygen biochemically because formate dehydrogenase activity is also essential for electron transfer from formate to oxygen (Pinsent, 1954). Also puzzling is why formate inhibits nitrosation by bacteria that have been grown in the absence of nitrate, even in mutants defective in the fermentative formate dehydrogenase, $\mathrm{FDH}_{\mathrm{H}}$. No single explanation can be offered to explain all of these observations. Rather, they suggest that formate plays several, conflicting roles in the multiple stages of DAN nitrosation, acting both to enhance and inhibit one or more of the chemical reactions involved after the enzyme-catalysed production of NO. The ability of formate to donate electrons via any of the three E. coli formate dehydrogenases and either menaquinone or ubiquinone to the respiratory nitrate reductase is only of secondary significance.

\section{ACKNOWLEDGEMENTS}

We are grateful to A. Böck, M. Chippaux, G. Giordano, M. Jones-Mortimer and V. Stewart for gifts of strains; S. Leach for many constructive comments and critically reading the manuscript; and Lesley Griffiths for valuable technical support. R.M. thanks the UK Medical Research Council for a Research Studentship. This research was supported by research grants GR/J26427 and G01944 from the BBSRC.

\section{REFERENCES}

Berg, B. L. \& Stewart, V. (1990). Structural genes for nitrateinducible formate dehydrogenase in Escherichia coli K-12. Genetics 125, 691-702.

Berg, B. L., Li, J., Heider, J. \& Stewart, V. (1991). Nitrate-inducible formate dehydrogenase in Escherichia coli K-12. I. Nucleotide sequence of the $f d n G H I$ operon and evidence that opal (UGA) encodes selenocysteine. J Biol Chem 266, 22380-22385.

Blasco, F., Nunzi, F., Pommier, J., Brasseur, R., Chippaux, M. \& Giordano, G. (1992). Formation of active heterologous nitrate reductases between nitrate reductases $\mathrm{A}$ and $\mathrm{Z}$ in Escherichia coli. Mol Microbiol 6, 209-219.

Böhm, R., Sauter, M. \& Böck, A. (1990). Nucleotide sequence and expression of an operon in Escherichia coli coding for formate hydrogenlyase components. Mol Microbiol 4, 231-243.
Calmels, S., Ohshima, H., Vincent, P., Gounot, A.-M. \& Bartsch, H. (1985). Screening of microorganisms for nitrosation catalysis at pH 7 and kinetic studies on nitrosamine formation from secondary amines by E. coli strains. Carcinogensis 6, 911-915.

Calmels, S., Ohshima, H., Rosenkranz, H., McCoy, E. \& Bartsch, H. (1987). Biochemical studies on the catalysis of nitrosation by bacteria. Carcinogenesis 8, 1085-1088.

Calmels, S., Ohshima, H. \& Bartsch, H. (1988). Nitrosamine formation by denitrifying and non-denitrifying bacteria: implication of nitrite reductase and nitrate reductase in nitrosation catalysis. J Gen Microbiol 134, 221-226.

Casadaban, M. J. \& Cohen, S. N. (1979). Lactose genes fused to exogenous promoters in one step using a $\mathrm{Mu}$-lac bacteriophage: in vivo probe for transcriptional control sequences. Proc Natl Acad Sci USA 76, 4530-4533.

Crooke, H. \& Cole, J. (1995). The biogenesis of $c$-type cytochromes in Escherichia coli requires a membrane-bound protein, DipZ, with a protein disulphide isomerase-like domain. Mol Microbiol 15, 1139-1150.

Darwin, A., Tormay, P., Page, L., Griffiths, L. \& Cole, J. (1993). Identification of the formate dehydrogenases and genetic determinants of formate-dependent nitrite reduction by Escherichia coli K12. J Gen Microbiol 139, 1829-1840.

De Bernadis, G., Guadagni, S., Pistoria, M. A., Amicucci, G., Masci, C., Herfath, C., Agnifili, A. \& Carboni, M. (1983). Gastric juice, nitrite and bacteria in gastroduodenal disease and resected stomach. Tumori 96, 231-237.

Enoch, H. G. \& Lester, R. L. (1975). The purification and properties of formate dehydrogenase and nitrate reductase from Escherichia coli. J Biol Chem 250, 6693-6705.

Forsythe, S. J., Dolby, J. M., Webster, A. D. B. \& Cole, J. A. (1988). Nitrate- and nitrite-reducing bacteria in the achlorhydric stomach. J Med Microbiol 25, 253-259.

Gest, H. \& Peck, H. D. (1955). Mechanism of the hydrogenlyase system. J Bacteriol 70, 326-334.

Gray, C. T. \& Gest, H. (1965). Biological formation of molecular hydrogen. Science 148, 186-192.

Griffiths, L. \& Cole, J. A. (1987). Lack of redox control of the anaerobically-induced nirB gene of Escherichia coli K12. Arch Microbiol 147, 364-369.

Grove, J., Tanapongpipat, S., Thomas, G., Griffiths, L., Crooke, H. \& Cole, J. (1996). Escherichia coli K-12 genes essential for the synthesis of $c$-type cytochromes and a third nitrate reductase located in the periplasm. Mol Microbiol 19, 467-481.

Hill, M. J., Hawksworth, G. \& Tattersall, U. (1973). Bacteria, nitrosamines and cancer of the stomach. Brit $J$ Cancer 28, 562-567.

Hussain, H., Grove, J., Griffiths, L., Busby, S. \& Cole, J. (1994). A seven gene operon essential for formate-dependent nitrite reduction to ammonia by enteric bacteria. Mol Microbiol 12, 153-163.

Ji, X. B. \& Hollocher, T. C. (1988). Mechanism for nitrosation of 2,3-diaminonaphthalene by Escherichia coli: enzymatic production of $\mathrm{NO}$ followed by $\mathrm{O}_{2}$-dependent chemical nitrosation. Appl Environ Microbiol 54, 1791-1794.

Kunisaki, N. \& Hayashi, M. (1979). Formation of $N$-nitrosoamines from secondary amines and nitrite by resting cells of Escherichia coli B. Appl Environ Microbiol 37, 279-282.

Leach, S. A. (1995). N-nitroso compounds. In Role of Gut Bacteria in Human Toxicology and Pharmacology, pp. 69-78. Edited by M. J. Hill. London: Taylor \& Francis. 
Leach, S. A., Cook, A. R., Challis, B. C., Hill, M. \& Thompson, M. (1979). Bacterial mediated $N$-nitrosamine reactions and endogenous formation of $\mathrm{N}$-nitroso compounds. In Relevance of $\mathrm{N}$-Nitroso Compounds to Human Cancer: Exposure and Mechanisms, pp. 396-399. Edited by H. Bartsch, I. K. O’Neill \& R. Schuite-Herman. Lyon: International Agency for Research on Cancer.

Leach, S. A., Thompson, M. H. \& Hill, M. J (1987). Bacterially catalysed $\mathrm{N}$-nitrosation reactions and their relative importance in the human stomach. Carcinogenesis 8, 1907-1912.

Lester, R. L. \& DeMoss, J. (1971). Effects of molybdenum and selenite on formate and nitrate metabolism in Escherichia coli. $J$ Bacteriol 105, 1006-1014.

O’Donnell, C. M. \& Edwards, C. (1992). Nitrosating activity in Escherichia coli. FEMS Microbiol Lett 95, 95-98.

Peck, H. D., Jr \& Gest, H. (1957). Formic dehydrogenase and the hydrogenlyase enzyme complex in coli-aerogenes bacteria. J Bacteriol 73, 706-721.

Pinsent, J. (1954). The need for selenite and molybdate in the formation of formate dehydrogenase by members of the Coliaerogenese group of bacteria. Biochem J 57, 10-16.

Rabin, R. S. \& Stewart, V. (1993). Dual response regulators (NarL and $\mathrm{NarP}$ ) interact with dual sensors ( $\mathrm{NarX}$ and $\mathrm{NarQ}$ ) to control nitrate- and nitrite-regulated gene expression in Escherichia coli K-12. J Bacteriol 175, 3259-3268.

Ralt, D. \& Tannenbaum, S. R. (1981). Role of bacteria in nitrosamine formation: N-nitroso compounds. Adv Chem Ser 174, 159-164.

Ralt, D., Wishnok, J. A., Fitts, S. \& Tannenbaum, S. R. (1988). Bacterial catalysis of nitrosation: involvement of the nar operon of Escherichia coli. J Bacteriol 170, 359-364.

Reed, P. I., Haines, K., Smith, P. L. R., House, F. R. \& Walters, C. L. (1981). Gastric juice $N$-nitrosamines in health and gastroduodenal disease. Lancet 2, 550-552.

Ruiz-Herrera, J. \& DeMoss, J. A. (1969). Nitrate reductase complex of Escherichia coli K-12: participation of specific formate dehydrogenase and cytochrome $b_{1}$ components in nitrate reduction. J Bacteriol 99, 720-729.

Sauter, M., Böhm, R. \& Böck, A. (1992). Mutational analysis of the operon $(h y c)$ determining hydrogenase 3 formation in Escherichia coli. Mol Microbiol 6, 1523-1532.

Sawers, G., Heider, J., Zehelein, E. \& Böck, A. (1991). Expression and operon structure of the sel genes of Escherichia coli and identification of a third selenium-containing formate dehydrogenase isoenzyme. J Bacteriol 173, 4983-4993.

Stewart, V. (1993). Nitrate regulation of anaerobic respiratory gene expression in Escherichia coli. Mol Microbiol 9, 425-434.

Taverna P. \& Sedgwick, B. (1996). Generation of an endogenous DNA-methylating agent by nitrosation in Escherichia coli. J Bacteriol 178, 5105-5111.

Received 14 February 1997; revised 6 May 1997; accepted 14 May 1997. 